\title{
Dilatometer Investigations of Reactive Sintering of Zinc Titanate Ceramics
}

\section{N. Obradovic ${ }^{1}$, N. Labus ${ }^{1}$, T. Sreckovic ${ }^{2}$, Lj. Zivkovic ${ }^{3}$, M. M. Ristic ${ }^{4}$}

\author{
Institute of Technical Sciences of SASA, Knez-Mihailova 35/IV, 11000 Belgrade, Serbia and Montenegro
${ }^{2}$ Center for Multidisciplinary Studies, University of Belgrade, Kneza Viseslava 1a, 11000 Belgrade, Serbia and Montenegro \\ ${ }^{4}$ Serbian Academy of Sciences and Arts, Knez-Mihailova 35, 11000 Belgrade, Serbia and Montenegro $=\mathrm{Zn}_{2} \mathrm{TiO}_{4}$ \\ $\mathrm{TiO}_{2} \mathrm{R}$ \\ - $\mathrm{ZnO}$ \\ $\square \mathrm{TiO}_{2} \mathrm{~A}$
}

Abstract

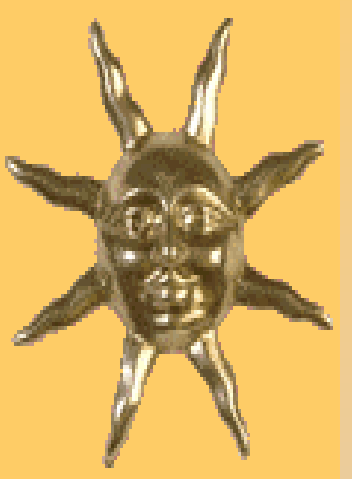

Starting powder mixtures of $\mathrm{ZnO}$ and $\mathrm{TiO}_{2}$, in the molar ratio that is in accordance with stoichiometry of zinc titanate $\mathrm{Zn}_{2} \mathrm{TiO}_{4}$, were mechanically activated using planetary ball mill during different time intervals from 0 to 90 minutes. $X$-ray diffraction analysis, scanning electron microscopy and non-isothermal dilatometric measurements were performed in order to investigate zinc titanates formation. Processes that occur during mechanical activation lead to the formation of a specific structure of obtained powders that promoted and accelerated solid-state reactions and densification during reaction sintering.
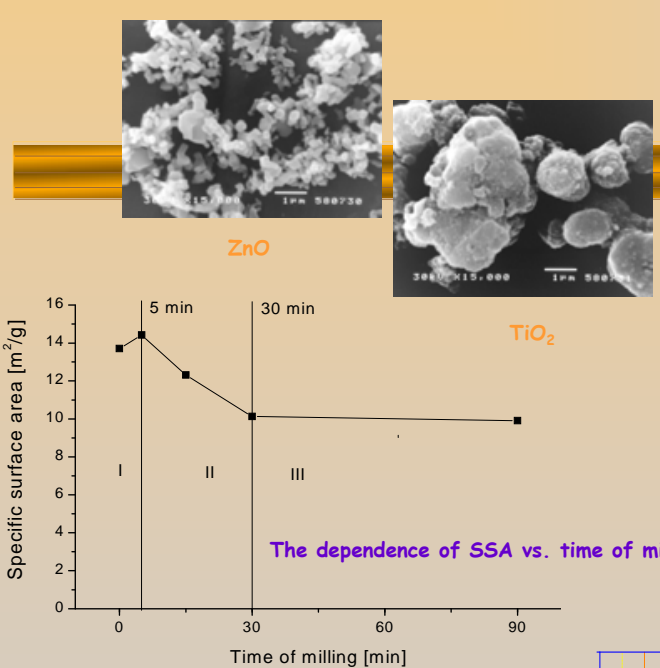

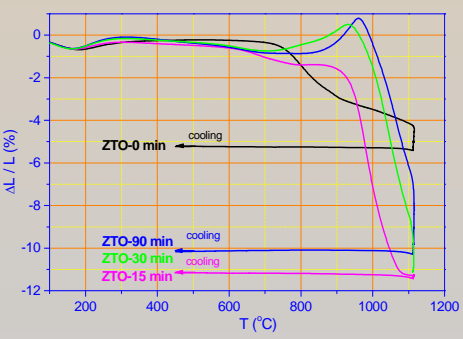

Relative shrinkage of the non-activated and various activated samples $10^{\circ} \mathrm{C} / \mathrm{min}$ and 2 hours holding

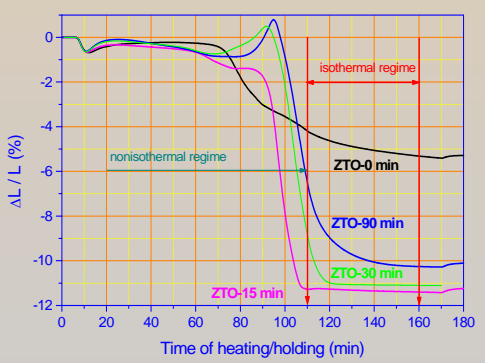

Relative shrinkage of the non-activated and various activated samples the $10^{\circ} \mathrm{C} / \mathrm{min}$ and 2 hours holding

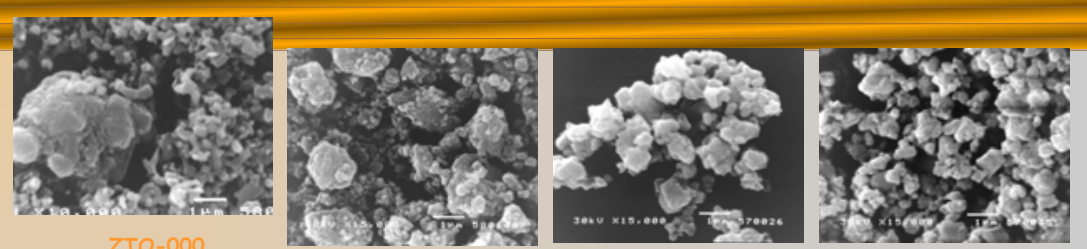

Scanning electron micrographs of starting $\mathrm{ZnO}, \mathrm{TiO}_{2}$, non-activated and the various activated powders

The influences of mechanical activation on solid state reaction and sintering in a mixture $2 \mathrm{ZnO}$ $\mathrm{TiO}_{2}$ were investigated. From the results of the present research it is possible to conclude that mechanical activation enables better compaction of activated powders without binders, but first of all that $\mathrm{Zn}_{2} \mathrm{TiO}_{4}$ ceramics could be obtained by mechanical activation after certain time with appropriate thermal treatment, i.e. heating rate and sintering time, at temperature lower then in case where no activated mixtures were used.

The main conclusion based on dilatometry and XRD analysis is that activation of only 15 minutes very successfully promotes solid-state reactions and sintering processes and establishes an optima thermal treatment of sintering at a significantly lower temperature than in the case of nonactivated mixture. 